in finding the extremity of the wire or threaded probe among the clots, which difficulty has suggested the watch-spring instruments of the shops, which is not always at hand, nor, henceforth, need be. Now fasten the hook formed at the extremity of the wire, and which projects anteriorly out of the nose through the mouth, into the projecting loop in the pharynx; and, having drawn it ont of the mouth, include as much lint as will suffice for a plug, securing it simply by twisting. Now retract it above the velum pendulum palati into the posterior nares, till the progress of the plug is arrested; next separate the ends hanging from the anterior nares, place a second plug between them, pressing it up to the noose previously mentioned, and securing this by a common knot, we finish the operation.

The advantages of this instrument are thus obvious-viz., the facility of obtaining its material in the poorest cottage upon an emergency; its projecting into the pharynx quite as well as the watch-spring instrument of the shops, thus rendering the operation almost momentary; its being strong enough to pass as a probe, and sufficiently delicate to tie as a ligature. Further, the way whereby the posterior plug is secured by twisting, enables the operator to increase the size of the plug instantly, should it be fonnd too small, and accidentally be drawn through anterior nares, which accident, were the plug secured by a knotted thread, would complicate the old, troublesome, and sometimes tedious operation.

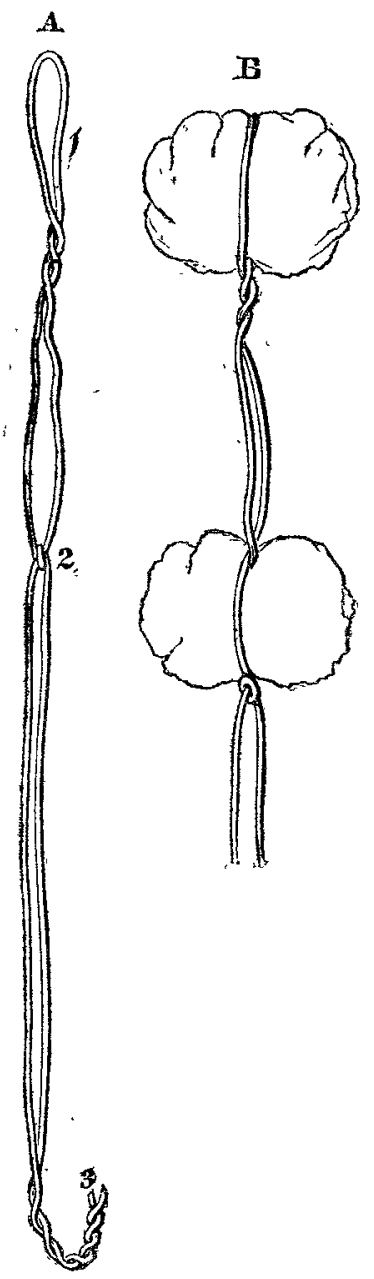

A, Instrument ready for operation-should be about fifteen inches long; $B$, The same after operation, inclosing the posterior pling by torsion, the anterior by knot, the ends cut off at anterior nares; 1 , Duplicature for posterior plug; 2, Noose for anterior plug; 3, Hook to draw the duplicature from pharynx.

Grosvenor-street, Cheltenham, 1849.

ON A

\section{CASE OF DISLOCATION OF THE HUMERUS.}

By H. R. HOSKINS, Esq., Surgeon, Hoxton-town.

I was called in the afternoon of Saturday, the 6th January, to a man who was stated to have injured his arm by a fall. On arriving, I found a man about forty years of age, stout, and muscular. He was sitting with his right arm so much raised that the elbow was very nearly on a level with the top of his head: he complained of great pain and numbness of the whole arm and forearm. The pain was increased by endeavouring to raise the arm still more, and became altogether unbearable on the slightest attempt to depress it, but it could be moved slightly backward and forward withont any great increase of pain. The head of the humerus could be plainly felt in the axilla, and passing over it were two rounded cords, most acutely sensitive to touch or pressure. With the assistance of a friend, I proceeded to reduce the dislocation. Extension was made for this purpose, at first in the only direction in which the arm could be placed, (i. e., very much upward.) When this had been continued a few minutes, I found that the elbow could be brought lower down, and the extension was then continued nearly at a right angle. After a very short interval, I placed my closed hand in the axilla and pressed the head of the bone upward, when it returned to the glenoid cavity with a snap, clearly perceptible both to myself and the patient. There were considerable pain and swelling about the joint, and numbness of the arm; the pain and swelling were quickly subdued, but the numbness, although con. stantly decreasing, still remains to some extent.

The account which I received of the accident, which happened only a few minutes before I was sent for, was, that the man, running out of his house with his arm raised to strike a blow, fell heavily on his back, the posterior part of his shoulder coming in violent contact with a stone, or some other projecting substance, and that he then found his arm fixed in the position I have described.

I have been induced to send this case for publication, believing it to be a very unusual one, as. I cannot remember to have heard or read of anything similar - the remarkable points being the raised position of the arm, and the situation of the nerves on the head of the humerus.

January 23,1849 .

\section{ON THE TREATMENT OF CHOLERA AT LEITH.} WITH A THEORY OF ITS PATHOLOGY.

By ANDREW C. LIVINGSTON, M.D., Leith.

Cholera having prevailed extensively in Leith and its vicinity, and many cases having fallen under my charge, I think it proper, while so many are publishing reminiscences of its former visitation, that those who have had an opportunity of observing the present epidemic should record the fruits of their experience and reflection. I submit the following remarks on its nature and treatment:-

In almost every instance where a favourable result has been obtained, I have found it preceded by profuse sweating, evidently indicating a crisis in the disease, and pointing out the proper object of treatment-viz., the production of a copious diaphoresis. When this could be procured, I invariably found the symptoms to remit, and the patient to fall into a profound slumber, on awakening from which he usually expressed himself much relieved, and by a continuance of the treatment, was eventually cured.

The principal remedies relied on were calomel and opium, in large doses, in men; and onium and camphor, in women; with warm stimulating draughts between the doses, the patient being surrounded wich bottles of hot water, and a sinapism placed over the stomach, taking care not to abandon the treatment hastily, though a few of the first doses might be rejected. By a perseverance in this treatment, the symptoms rapidly alate, and a distinct shivering is frequently observed to precede the crisis of sweating. The only symptom which may prove troublesome, after the more formidable ones have been subdned, is a constant retching. This I found most easily relieved by the use of hydrocyanic acid.

The principal object of this communication, however, is not to recommend any precise treatment, but to indicate some principle upon which treatment ought to be based. All attenupts to treat this disease as having a gastro-enteric location liave been signally unsuccessful, and rest on narrow and fallacious grounds; indeed, a short acquaintance with the present epidemic is sufficient to dispel all such illusion. The matters discharged are not like the evacuations which occur in diarrhceas, and the cramps and subsequent collapse are not in proportion to the matters discharged. In some cases of severe cramps and collapse, little or no vomiting and purging were observed, showing that these symptoms could not have been produced by the exhaustion of the serum of the blood, but were the distinct product of the virus.

If cholera, then, has not a gastro-enteric seat, where ought it to be placed? I have no hesitation in asserting that, it 